\section{A produção intelectual de mulheres negras como teoria social crítica}

COLLINS, Patricia Hill. Pensamento feminista negro: conhecimento, consciência e a política do empoderamento. São Paulo: Boitempo, 2019.

Bruna Cristina Jaquetto Pereira (https://orcid.org/0000-0003-3213-8672), Instituto de Relações Internacionais, Universidade de Brasília (UnB), Brasília, Distrito Federal, Brasil'.

$\square$ m 2019, quase 30 anos após o seu lançamento em 1990, o clássico do feminismo negro Black feminist thought, da socióloga estadunidense Patricia Hill Collins, finalmente ganhou uma edição em português. De toda forma, a obra é mais que bem-vinda, dada a relevância dos argumentos principais de Collins para a produção intelectual e para o modo de funcionamento da sociedade brasileira contemporânea.

Dividido em três partes e com um total de 12 capítulos, Pensamento feminista negro é um livro escrito em linguagem e formato acessíveis - uma marca registrada da autora -, embora conte com uma profusão de argumentos e conteúdo denso. De início, Collins afirma que mulheres negras estadunidenses de épocas distintas e por meio de diferentes estratégias de produção de conhecimento (acadêmica, musical, poética etc.) lançaram as bases para uma tradição intelectual de mulheres afro-americanas que apresenta compreensões particulares do "eu", da comunidade e da sociedade. Não se trata de uma forma de ver "natural" das mulheres negras, e sim de elaborações convergentes porque derivadas de sua inserção como grupo numa sociedade configurada por opressões de gênero, raça e classe. Para Collins, o pensamento feminista negro é produzido como "conhecimentos de resistência" (oppositional knowledge), parte da relação dialética entre opressão e ativismo.

A essa apresentação do pensamento feminista negro, no primeiro capítulo sucede-se à exposição dos quatro objetivos específicos do livro apresentar as temáticas recorrentes do pensamento feminista negro; empregar e difundir o uso do paradigma interpretativo interseccional; expor as características epistemológicas distintivas do pensamento feminista negro; promover as contribuições do feminismo negro para o
Recebido: 30.11 .20 Aprovado: 19.03.21

I. Bruna Cristina Jaquetto Pereira, doutora em sociologia pela Universidade de Brasília (UnB), é professora voluntária do Departamento de Relações Internacionais na Universidade de Brasília. <brunacjpereira@ gmail.com>. 
empoderamento das afro-americanas. Cada um dos objetivos está alinhado ao objetivo geral, que é descrever e analisar o pensamento feminista negro, discutir a sua importância e ainda contribuir para que ele se desenvolva como uma teoria social crítica.

É também no capítulo inicial que a autora explicita o paradigma interpretativo que emprega e que orienta os seus argumentos no decorrer da obra. Para Collins, a opressão congrega sempre diferentes tipos: de classe, raça, gênero, sexualidade, nacionalidade etc. "Interseccionalidade" designa a combinação de dois ou mais tipos específicos de opressão, tal como em "interseccionalidade de gênero e raça" ou "de raça e sexualidade". Cada sociedade, em cada momento histórico, dispõe de uma "matriz de dominação" única, caracterizada por um arranjo particular de opressões interseccionadas.

No segundo capítulo, Collins delineia o conjunto de aspectos que tornam o pensamento feminista negro único: a reação à opressão; a heterogeneidade de respostas a ela; a resistência estimulada por uma determinada posição grupal dentro da sociedade; as contribuições de intelectuais afro-americanas; o dinamismo e a capacidade de responder à mudança; a relação com outros projetos de justiça social. Apesar de indicar consonâncias, a autora destaca também a variabilidade das vivências e dos tipos de produção entre mulheres negras, a mudança do contexto social ao longo da história, e a viabilidade e necessidade de alianças com outros grupos sociais. Para Collins, as características enunciadas não estão restritas ao pensamento feminista negro, é antes a convergência particular de tais aspectos que o torna singular.

A segunda parte do livro, que abrange os capítulos 3 a 9, aborda os temas que a autora considera centrais para o feminismo negro: o trabalho, a família e a relação entre opressão e ativismo. A obra leva em conta a forma como inúmeras intelectuais negras tratam da inserção precária do grupo feminino negro no mercado de trabalho e o trabalho não remunerado que desempenham junto a suas famílias estendidas e comunidades, que, embora desvalorizado, contribui para o bem-estar das famílias e, frequentemente, supre funções que deveriam ser desempenhadas pelo Estado. O capítulo 3 traz ainda uma discussão sobre a maternidade nas famílias negras, ressaltando o papel das mães na transmissão de valores, portanto, na articulação de uma cultura de resistência ao racismo. Ao considerar o trabalho e as relações familiares a partir da perspectiva de intelectuais negras, Collins desafia as análises que enxergam a sociabilidade dos grupos negros como "desviante" ou "patológica", tendo em vista definições normativas que são, também elas, racializadas. Assim, a socióloga questiona compreensões tradicionais de trabalho, a divisão entre esfera pública e esfera privada, o padrão do homem como provedor familiar e, com efeito, a própria noção de família. 
Segundo Collins, a opressão engloba a dimensão econômica, política e ideológica. É no capítulo 4 que a autora trata de um conceito-chave para a dimensão ideológica: o de "imagens de controle". Imagens de controle são representações estereotipadas de mulheres negras que operam como justificativas ideológicas para a sua opressão, na medida em que favorecem que a pobreza, o racismo e o sexismo a que estão submetidas pareçam normais, naturais e inevitáveis. Trata-se de um mecanismo de objetificação e subordinação, um recurso para que a diferença racial e de gênero seja compreendida em termos binários e como hierarquia, a partir da qual a identidade e a realidade das mulheres negras é definida pelos grupos dominantes. Legitimam, assim, a exploração econômica e a negação dos direitos de cidadania às mulheres negras.

A obra apresenta as principais imagens de controle no contexto dos Estados Unidos. A mammy representa a mulher negra junto à sociedade branca, a serva doméstica leal e obediente, que aceita a própria subordinação e exploração econômica. A "matriarca negra" diz respeito às mulheres negras em seus próprios lares, e faz parte da racialização da chefia feminina das unidades domésticas, que é então tomada como causa da pobreza da população negra. É a mãe negra "má" que emascula homens e meninos e, negligente com filhos e filhas, é responsável pela "anomia" atribuída ao grupo negro. A "mãe dependente do Estado" - assim como uma sua variação mais recente, a "rainha da assistência social" - é a figura que estigmatiza aquelas que fazem uso de benefícios sociais garantidos por lei. Essa imagem rotula as mulheres negras pobres como preguiçosas e oportunistas; direcionada a atender necessidades da economia política, é ainda utilizada para regular a sua fecundidade, julgando-a perigosa. Por sua vez, a imagem da "dama negra" aplica-se às profissionais negras de classe média que aderem à política de respeitabilidade ${ }^{1}$ : elas trabalham mais que todos e, por isso mesmo, "negligenciam" seus papéis como "mulheres", tornando-se por demais assertivas. Já a "jezebel" (em outras versões, "prostituta" ou "hoochie") designa a "anormalidade" sexual das mulheres negras, retratadas como dotadas de um apetite sexual excessivo.

Além da leitura sobre a opressão, também as estratégias de resistência (coletivas e individuais, visíveis e ocultas) adotadas por mulheres negras ocupam um lugar de destaque no livro. A tanto se dedicam os capítulos 5 a 9. No capítulo 5, Collins, inspirada na ideia de dupla consciência², aborda a questão da "autodefinição", ou seja, a maneira como mulheres negras, em sua luta contra a opressão e particularmente contra as imagens de controle, constroem formas de conhecimento que são essenciais para a sua sobrevivência como grupo, ao facilitar a transição da posição de vítima à de seres humanos criativos. Para a autora, a autodefinição é capaz de forjar o autorrespeito, a autonomia, o empoderamento e a capacidade de transfor-

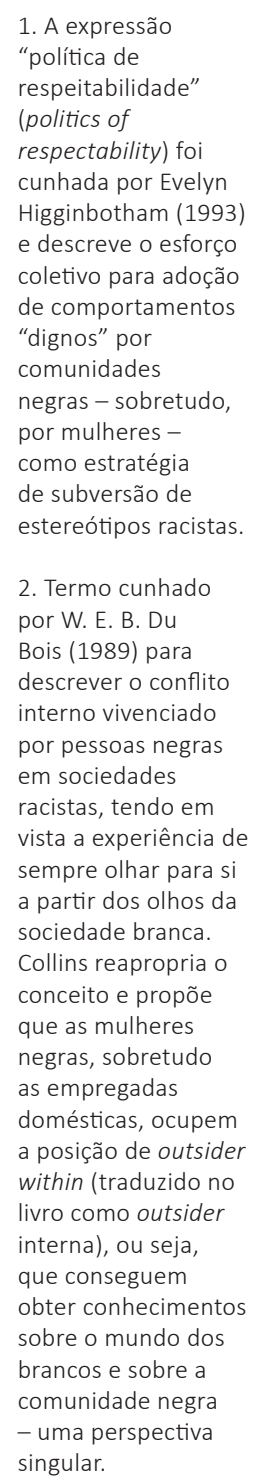

1. A expressão

"política de

(politics of respectability) foi cunhada por Evelyn Higginbotham (1993) coletivo para adoção de comportamentos "dignos" por comunidades negras - sobretudo por mulheres como estrategia de subversão de 2. Termo cunhado por W. E. B. Du Bois (1989) para interno vivenciado por pessoas negras em sociedades racistas, tendo em sempre olhar para si a partir dos olhos da sociedade branca. Collins reapropria o conceito e propõ que as mulheres negras, sobretudo as empregadas domésticas, ocupem a posição de outsider within (traduzido no interna), ou seja, que conseguem obter conhecimentos sobre o mundo dos comunidade negra singular. 
mação, e é concebida nos mais diversos espaços: na convivência nas igrejas negras, entre amigas, na função de cuidadoras e entre membros da família, na tradição de mulheres negras no Blues, como escritoras.

Na sequência, Collins aplica os princípios acima delineados a certas temáticas. Os capítulos 6, 7 e 8 constituem exercícios de contraposição entre as visões tradicionais e as perspectivas "autodefinidas" quanto aos temas da sexualidade, dos relacionamentos afetivos e da maternidade das mulheres negras.

Como um desdobramento, o livro chega ao capítulo 9 com a proposta de ressaltar a importância da atuação política das mulheres negras. A autora sublinha que as definições tradicionais de atuação política adotadas pelas ciências sociais consideram sobretudo as atividades públicas, os enfrentamentos institucionais, oficiais e visíveis. Dessa forma, deixam de lado as ações voltadas para a sobrevivência grupal, igualmente importantes para o grupo negro e que são desenvolvidas primordialmente por mulheres negras. Um segundo resultado dessa definição é que a ausência ou a escassez de mulheres negras em postos oficiais da política é lida como baixo nível de ativismo, o que invisibiliza as lutas das mulheres negras. Contudo, além dos esforços para promover a sobrevivência do grupo, mulheres negras também agiram e agem para viabilizar transformações institucionais, atuando em organizações que promovem direitos civis, sindicatos, coletivos feministas, boicotes e revoltas, ou mesmo em seus trânsitos cotidianos pelo mercado de trabalho, igrejas, instituições de ensino, em sua relação com a mídia e com os governos.

A terceira e última parte do livro abrange os capítulos 10, 11 e 12, e dedica-se à análise da relação entre conhecimento e poder. O capítulo 10 marca um movimento em direção a uma visão transnacional, afrodiaspórica, que reconhece as aproximações e a necessidade de solidariedade entre mulheres negras de diferentes sociedades, tendo em vista a situação comum de pobreza e discriminação que enfrentam, ao mesmo tempo em que ressalta a necessidade de se contemplar as particularidades históricas e as configurações da matriz de dominação própria de cada contexto.

A epistemologia negra feminista é o tema do capítulo 11. Critérios políticos, afirma Collins, influenciam o processo de validação do conhecimento. Uma vez que as instâncias validadoras são dominadas por um grupo dominante homogêneo - o dos homens brancos -, é à aprovação deles que as reivindicações de conhecimento ficam sujeitas. Tais especialistas, como todos os indivíduos, trazem consigo um conjunto de experiências sedimentadas que refletem a sua inserção como grupo na matriz de dominação, tendo em vista as opressões de raça, gênero, classe, sexuali- 
dade e nação. O resultado é a instituição de critérios que deslegitimam a produção intelectual de mulheres negras como conhecimento.

Segundo a autora, isso não impede que mulheres negras produzam conhecimento. Como outros grupos subordinados, elas desenvolvem um ponto de vista específico, valendo-se de um modo alternativo de produção e validação do conhecimento - ou seja, de uma epistemologia própria. Para Collins, tais critérios, segundo o pensamento feminista negro, são: a experiência vivida (ao invés da abstração pura); o diálogo entre sujeitos (e não a noção de separação entre sujeito e objeto); a ética do cuidar (o respeito à singularidade individual, a legitimidade das emoções no diálogo e a capacidade de empatia); e a ética da responsabilidade pessoal (que torna as pessoas responsáveis por aquilo que reivindicam como conhecimento). Collins defende que os grupos sociais produzem conhecimentos localizados e parciais, sempre inacabados, que devem ser compartilhados de modo a expandir perspectivas, e sem que o ponto de vista de um determinado grupo suprima os conhecimentos produzidos pelos demais.

O último capítulo versa também sobre a relação entre conhecimento e poder, agora com vistas à resistência às opressões. A autora argumenta que o pensamento feminista negro empodera as mulheres negras de duas formas. Em primeiro lugar, lança um novo olhar sobre as injustiças sociais: ao levar em conta o paradigma interseccional e a agência individual e coletiva de mulheres negras, ele reconceitua as relações sociais de dominação e resistência. Em segundo lugar, o pensamento feminista negro fornece uma epistemologia que permite criticar o corpo de conhecimento reconhecido como tal, e ainda que as mulheres negras definam sua realidade em seus próprios termos.

É também neste capítulo que Collins apresenta sua interpretação da arquitetura de poder em uma sociedade. Para a autora, cada matriz de dominação organiza-se a partir de quatro domínios inter-relacionados de poder. O domínio estrutural refere-se à forma como as instituições sociais organizam a opressão das pessoas negras e reproduzem sua subordinação ao longo do tempo. Neste âmbito, empoderamento diz respeito à mudança de instituições e leis. O domínio disciplinar trata do gerenciamento da opressão, valendo-se da burocracia e das técnicas de vigilância. A resistência é praticada por mulheres negras que integram as organizações responsáveis pelo controle disciplinar e que buscam direcioná-la a fins humanísticos. O domínio hegemônico é aquele que justifica práticas opressivas, e engloba a manipulação de ideias, imagens, símbolos e ideologias. Aqui, o empoderamento se dá pela construção de conhecimentos contra-hegemônicos. Por fim, o domínio interpessoal designa as práticas rotineiras cotidianas. Nele, a resistência se dá pela 
quebra de rotinas que explicitam práticas opressivas -, como, por exemplo, estratégias empregadas por pessoas negras monitoradas por seguranças em lojas.

Termino minhas considerações sobre a obra ressaltando um comentário que figura nas primeiras páginas do livro, no "Prefácio à edição brasileira". Pensamento feminista negro oferece ferramentas teórico-conceituais e metodológicas potentes para o feminismo negro na academia brasileira. Porém, como observa Collins, é preciso ter em mente que as experiências das mulheres negras estadunidenses não são universais; tampouco o conteúdo do livro se aplica automaticamente à realidade brasileira.

O Brasil não tem mammy, tem "mãe preta" - a quem Lélia Gonzalez (Rios \& Lima, 2020) atribui a "africanização" da cultura brasileira, contra os esforços de branqueamento/europeização por parte das elites nacionais. Não tem Jezebel, tem "mulata" - uma figura muito mais recorrente no imaginário brasileiro do que sua contraparte estadunidense. Não teve segregação racial ou luta por direitos civis, mas conta com um historicamente complexo e variado movimento negro (Pereira, 2019; Rodrigues, 2020). Os negros e as negras somam menos de $13 \%$ da população dos Estados Unidos; no Brasil, somos maioria. Eles são a maior potência mundial; nós, um "país em desenvolvimento". Desse modo, a leitura da obra será tão mais frutífera quanto mais agregar uma perspectiva afro-diaspórica. Para tanto, é necessário integrar suas contribuições às características da sociedade brasileira, e ainda colocá-las em diálogo com as contribuições de autoras como Lélia Gonzalez (Rios \& Lima, 2020), Sueli Carneiro (2018) e Beatriz Nascimento (Ratts, 2006), e com a produção de autoras brasileiras ainda desconhecidas, dadas as políticas de "supressão" (Collins, 2019: 37) do conhecimento produzido por mulheres negras.

\section{Referências}

CARNEIRO, Sueli. Escritos de uma vida. Belo Horizonte: Letramento, 2018.

DU BOIS, W. E. B. The souls of Black folk. New York: Penguin Books, 1989.

HIGGINBOTHAM, Evelyn B. Righteous discontent: the women's movement in the Black Baptist Church, 1880-1920. Cambridge, MA: Harvard University Press, 1993.

PEREIRA, Ana Claudia Jaquetto. Intelectuais negras brasileiras: horizontes politicos. Belo Horizonte: Letramento, 2019.

RATTS, Alex. Eu sou Atlântica: sobre a trajetória de vida de Beatriz Nascimento. São Paulo: Instituto Kuanza; Imprensa Oficial, 2006. 
RIOS, Flavia; LIMA, Márcia (Orgs.). Por um feminismo afro-latino-americano: ensaios, intervenções e diálogos. Rio de Janeiro: Zahar, 2020.

RODRIGUES, Cristiano. Afro-latinos em movimento: protesto negro e ativismo institucional no Brasil e na Colômbia. Curitiba: Editora Appris, 2020.

(c) (1) (8) 
